ISSN 2236-0859

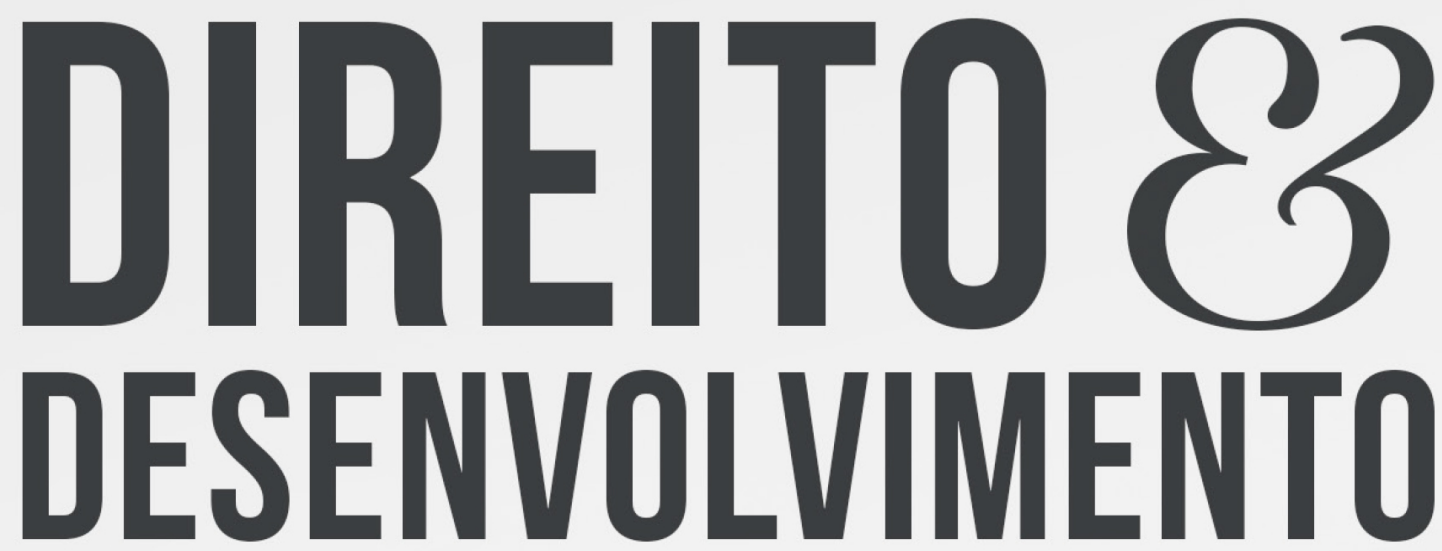

REVISTA DO PROGRAMA DE PÓS-GRADUAÇ̃̃O EM DIREITO MESTRADO EM DIREITO E DESENVOLVIMENTO SUSTENTÁVEL

O APRIMORAMENTO DO SISTEMA DE SEGURANÇA PÚBLICA E SEU ADEQUADO FINANCIAMENTO

ROY REIS FRIEDE 


\title{
O APRIMORAMENTO DO SISTEMA DE SEGURANÇA PÚBLICA E SEU ADEQUADO FINANCIAMENTO
}

\section{THE IMPROVEMENT OF THE PUBLIC SAFETY SYSTEM AND ITS ADEQUATE FUNDING}

Recebido: 13/01/2020

Aprovado: 01/12/2020

Roy Reis Friede

\section{RESUMO:}

A violência urbana é um dos principais problemas com os quais diferentes países precisam lidar. A violência atinge, hoje em dia, a maioria das cidades brasileiras, trazendo uma sensação de insegurança e tendo reflexos nas mais diferentes áreas da vida dos cidadãos. O trabalho pretende fazer algumas reflexões sobre o financiamento da segurança pública e o sucateamento das forças policiais, mais precisamente na cidade do Rio de Janeiro. Também será feita uma análise crítica sobre o uso das Forças Armadas em substituição aos órgãos responsáveis pela segurança pública. Serão utilizadas matérias que circularam em veículos da grande imprensa para ilustrar como o sucateamento dos órgãos que compõem o sistema de segurança pública no Brasil é mostrado, ou denunciado, para a população em geral.

Palavras-chave: Violência Urbana. Forças Armadas. Segurança Pública. Direitos Humanos. Ordem Pública.

\begin{abstract}
:
Urban violence is one of the main problems that different countries have to deal with. Violence affects most Brazilian cities today, bringing a sense of insecurity and having a reflection on the most different areas of citizens' lives. The work intends to make some reflections on the financing of public safety and the scrapping of the police forces, more precisely in the city of Rio de Janeiro. There will also be a critical analysis of the use of the Armed Forces in place of the bodies responsible for public security. We will use materials circulated in vehicles of the main press to illustrate how the scrapping of the organs that compose the public security system in Brazil is shown, or denounced, to the general population.
\end{abstract}

Keywords: Urban Violence. Armed Forces. Public Security. Human Rights. Public Order.

\footnotetext{
1 Doutor em Direito Público (UFRJ), Mestre em Direito do Estado (UGF) e em Direito Público (UFRJ). É Desembargador Federal, Presidente do Tribunal Regional Federal da $2^{\underline{a}}$ Região, Membro Efetivo do Conselho da Justiça Federal (CJF), ex-Membro do Ministério Público; Professor Titular e Membro do Conselho Consultivo do Mestrado Profissional Multidisciplinar em Desenvolvimento Local e ex-Coordenador para a Implantação do Programa de Mestrado em Direito da UNISUAM; Professor Emérito da Escola de Comando e Estado-Maior do Exército (ECEME), Professor Honoris Causa da Escola de Comando e Estado-Maior da Aeronáutica (ECEMAR), Professor de Direito Constitucional da Escola da Magistratura do Estado do Rio de Janeiro (EMERJ), Professor Adjunto da Universidade Federal do Estado do Rio de Janeiro e fundador do Mestrado em Direito da UNESA/RJ. Graduado em Ciências Jurídicas, concluiu, também, os bacharelados em Administração (UCAM), Engenharia (UERJ/USU), Arquitetura (USU) e Economia (UFRJ), além de Licenciatura em Matemática (AVM/UCAM). email: assessoriareisfriede@hotmail.com
} 


\section{INTRODUÇÃO}

Segundo dados divulgados pelo Instituto de Segurança Pública/ISP na publicação "Séries históricas anuais de taxa de letalidade violenta no estado do Rio de Janeiro e grandes regiões" (2019), as mortes por letalidade violenta - que correspondem ao somatório das mortes por homicídio doloso, roubo seguido de morte (latrocínio), lesão corporal seguida de morte e morte decorrente de intervenção de agente do Estado - perfazem um total de 6.695 somente no estado do Rio de Janeiro em 2018.

A violência urbana é um dos principais problemas com os quais diferentes países precisam lidar em suas políticas públicas. Como se não bastasse a ousadia da criminalidade contemporânea, que cada vez mais insiste em aterrorizar a sociedade, a ausência de integração entre os entes (União, Estados, Distrito Federal e Municípios) que fazem parte do denominado Sistema Constitucional de Segurança Pública (art. 144 da CF/1988) é flagrante, sendo apontada como uma das inúmeras causas que contribuem para o atual quadro de desprestígio - em todos os aspectos possíveis - que paira sobre as forças policiais do País, conforme reconhecido, inclusive, em Audiência Pública realizada em 19 de setembro de 2017, na Comissão de Constituição, Justiça e Cidadania (CCJ) do Senado Federal.

\footnotetext{
Um maior protagonismo da União na segurança pública e integração e coordenação entre os órgãos que atuam no setor podem frear o crescimento da violência e reverter o problema, afirmaram [...] os convidados de audiência pública na Comissão de Constituição, Justiça e Cidadania (CCJ). (SEGURANÇA PÚBLICA, 2017)
}

Forma-se, em tal contexto onde imperam a desarmonia e o descrédito institucionais, um perfeito caldo de cultura para a atuação das denominadas empresas (regulares ou irregulares) de segurança privada, cujos "serviços" oferecidos envolvem desde a instalação de câmeras de vigilância ao fechamento de vias públicas por meio de cancelas e grades, tudo em evidente violação às normas urbanísticas e de trânsito editadas por um Estado fraco, e que muitas das vezes não consegue sequer fazer cumprir as leis por ele mesmo estabelecidas, problema perigosíssimo e que pode nos conduzir à barbárie. Cumpre, então, retomar as rédeas da situação, o que demanda instituições policiais eficientes e providas da necessária autoridade estatal, como também de recursos materiais e armamentos.

Revelando semelhante preocupação, o Juiz Roberto Caldas, Presidente da Corte Interamericana de Direitos Humanos, ao comentar sobre a morte da Vereadora Marielle Franco, crime que "expõe traços de barbárie", advertiu que "não há futuro sem Estado de Direito e Democrático", e que "não pode haver vazio de autoridade num Estado de Direito", frases perfeitamente aplicáveis à delicada situação na qual o Brasil se encontra (CARIELLO, 2018, p. 13).

Não há dúvida, portanto, a respeito de quão deficiente é o sistema de segurança pública do país, fazendo com que as pessoas passem a recorrer a estratégias heterodoxas. E tal precariedade sistêmica - que, registre-se, alcança todos os órgãos elencados no art. 144 da Constituição Federal (1988), notadamente as Polícias Militares e as Polícias Civis vem ensejando o frequente emprego das Forças Armadas - destinadas, prima facie, à defesa nacional - em operações de garantia da lei e da ordem (GLO), em substituição aos órgãos primariamente responsáveis pela segurança pública.

A violência atinge, hoje em dia, a maioria das cidades brasileiras, trazendo uma sensação de insegurança e tendo reflexos nas mais diferentes áreas da vida dos cidadãos. Este trabalho pretende fazer algumas reflexões sobre o precário financiamento da segurança pública e o sucateamento das forças policiais, mais precisamente na cidade do Rio de Janeiro, 
cartão postal do país e que sofre com as consequências de uma segurança pública frágil e que não consegue apresentar resultados satisfatórios para a população. Também será feita uma análise sobre o uso das Forças Armadas em operações de garantia da lei e da ordem (GLO), em substituição aos órgãos primariamente responsáveis pela segurança pública.

O Brasil, sendo uma República Federativa, e para se constituir como um Estado Democrático de Direito, segue o princípio da separação dos poderes. A clássica "Teoria da Separação dos Poderes”, proposta por Montesquieu (2000), apresenta a divisão dos poderes políticos e suas respectivas áreas de atuação: Legislativo, Executivo e Judiciário. Para o autor, o perigo em se deixar numa única mão a responsabilidade de legislar, administrar e julgar colide na possibilidade de que o indivíduo que tem um poder ilimitado possa dele abusar, por isso os poderes devem atuar de forma separada, mas ainda mantendo a independência e harmonia. Mas um quarto poder surge, representado pelos meios de comunicação, se incumbindo da responsabilidade de fiscalizar e denunciar os abusos cometidos pelos três poderes instituídos, incluindo as possíveis violações de direitos dos cidadãos que vivem sob regimes democráticos.

A partir da compreensão de que os meios de comunicação exercem uma força sobre a sociedade, principalmente pelo seu alcance, e que essa força influencia na percepção que os indivíduos passam a ter do seu entorno, serão utilizadas matérias que circularam em veículos da grande imprensa para ilustrar como o sucateamento dos órgãos que compõem o sistema de segurança pública no Brasil, especialmente as forças policias, acaba sendo mostrada, ou denunciada, para a população de maneira geral.

\section{AS FORÇAS ARMADAS E A SEGURANÇA PÚBLICA}

Segundo relatório do Programa das Nações Unidas para o desenvolvimento, "O nível de insegurança impede o desenvolvimento humano dos latino-americanos" (PNUD, 2013). Ao mesmo tempo em que é possível constatar que a região tem economias mais fortes, menos pobreza e democracias mais consolidadas, também se percebe "uma epidemia de violência, acompanhada pelo crescimento e pela disseminação do crime, assim como o aumento do temor entre os cidadãos" (PNUD, 2013). Diante das múltiplas notícias veiculadas nos meios de comunicação sobre o aumento da sensação de insegurança e das ocorrências violentas no cotidiano brasileiro, é possível inferir que a insegurança e a violência têm sido um dos obstáculos ao desenvolvimento econômico e social do país.

Segurança pública é um conceito ainda não devidamente sedimentado no Brasil, embora a temática persista atual e geralmente carregada de certa dose de polêmica. Decorridos quase trinta anos da promulgação da Constituição da República Federativa do Brasil, de 1988 (CF/1988), suspeita-se que a Carta Magna, ao manter a estrutura então existente, não logrou resolver os problemas atinentes ao tema, não obstante haver definido os pressupostos da atuação nessa área, em termos dos órgãos que são por ela responsáveis e suas respectivas competências. Não chegou, porém, a definir com precisão o que significa segurança púbica nem prover-lhe os instrumentos de atuação conforme o pretendido epíteto de 'cidadã', que perpassa a pretensa égide constituinte. (ROCHA, 2016, p. 4)

Para a Organização dos Estados Americanos (OEA), que congrega 35 Estados independentes das Américas e constitui o principal fórum governamental político, jurídico e social, baseando-se na democracia, nos direitos humanos, na segurança e no desenvolvimento:

O conceito de segurança pública passou a ser entendido a partir de uma perspectiva mais complexa do que em décadas passadas. As ameaças de segurança vão além da esfera militar tradicional para incluir os problemas que têm um impacto direto na vida 
das pessoas, como a violência de gangues, criminalidade, tráfico de drogas, armas ou seres humanos. (ORGANIZAÇÃO..., 2019)

A área de Segurança Pública é uma das mais preocupantes no cenário nacional e o tema aparece, diariamente, nos principais noticiários brasileiros. Há tempos o país vem passando por uma crise que gera uma sensação de insegurança reinante entre a população. A garantia de ir e vir com segurança está prevista pela Constituição Federal (1988) e se constitui em um direito fundamental, assim como moradia, saúde, educação, lazer, todos devendo ser assegurados pelo Estado.

\footnotetext{
No Brasil, a segurança pública é fundamentalmente da competência dos estados. Cada um deles tem, por exemplo, suas forças policiais - Polícia Civil e Polícia Militar - e seu Tribunal de Justiça, conforme o modelo federativo. A Polícia Federal, por seu lado, tem porte reduzido - inferior ao de muitas polícias estaduais - e o sistema de justiça criminal federal tem competências limitadas a determinados crimes. Por isso, o papel do poder federal foi, sobretudo, incentivar, por meio de financiamentos, intervenções nos estados, que atendam certos requisitos técnicos e políticos. As prefeituras, por seu lado, têm um papel na área da prevenção, principalmente, embora a expansão das guardas municipais inclua também tarefas de repressão. (CANO, 2006, p. 138)
}

Ainda segundo Cano (2006), a percepção da insegurança por parte dos cidadãos provocou uma pressão na sociedade para que fossem tomadas medidas no campo da segurança pública independente de suas competências oficiais, porém, "a difícil situação financeira dos estados impede investimentos significativos, o que tem contribuído para o aumento dos poderes municipal e federal neste campo" (CANO, 2006, p. 138).

Segundo Rolim (2007), o Brasil, nas duas últimas décadas pelo menos, vem apresentando um problema novo no que diz respeito à segurança pública, que é o aumento das taxas de homicídios, principalmente nas regiões metropolitanas, acompanhadas pelo aumento de práticas violentas propostas por grupos vinculados ao tráfico de armas e drogas e também por manifestações coletivas de grupos sociais nos principais centros urbanos. Embora a publicação seja de $\mathbf{2 0 0 7}$, podemos perceber que o problema persiste até os dias de hoje no país. E, para Rolim, na área das políticas de segurança pública no Brasil existe uma resistência incomum à inovação, além de um apego à tradição muito consolidado, sendo isto parte do problema a ser enfrentado (ROLIM, 2007).

É a partir da percepção da insegurança e da realidade da violência que se torna possível compreender a importância da área de segurança pública e suas políticas, que precisam ser eficazes e inovadoras, visto que o cenário da insegurança e da violência não é uniforme e demanda ações pontuais relacionadas às necessidades da população.

De acordo com o previsto no art. 142 da Constituição Federal (1988), as Forças Armadas, compostas por Marinha, Exército e Aeronáutica "são instituições nacionais permanentes e regulares [...] e destinam-se à defesa da Pátria, à garantia dos poderes constitucionais e, por iniciativa de qualquer destes, da lei e da ordem" (BRASIL, 1988). Lendo o texto constitucional entendemos que cabe às Forças Armadas garantir a lei e a ordem, e não uma ou outra, o que significa garantir o cumprimento das leis e a preservação da ordem pública.

No capítulo III da Constituição Federal, que trata Da Segurança Pública, o art. 144 define que "[...] a segurança pública, dever do Estado, direito e responsabilidade de todos, é exercida para a preservação da ordem pública e da incolumidade das pessoas e do patrimônio [...]" (BRASIL, 1988).

Ordem Pública - Conjunto de regras formais, que emanam do ordenamento jurídico da Nação, tendo por escopo regular as relações sociais de todos os níveis, do interesse 
público, estabelecendo um clima de convivência harmoniosa e pacífica, fiscalizado pelo poder de polícia, e constituindo uma situação ou condição que conduza ao bem comum. (BRASIL, 1983)

No artigo 29 da Declaração Universal dos Direitos Humanos, inciso II, consta que é dever do Estado respeitar os direitos fundamentais para se alcançar o bem estar social e garantir a ordem pública, o que não deixa dúvidas de que ordem pública englobe segurança pública como forma de se manter a dignidade da pessoa humana (ONU, 1948).

Não obstante a possibilidade constitucional de emprego das instituições militares em missões de segurança pública, bem como a concreta necessidade de utilizá-las em casos de grave comprometimento da ordem pública, a regra e a lógica, obviamente, não podem ser essa. O uso constante das Forças Armadas em operações de garantia da lei e da ordem (GLO) acaba por abrir um debate sobre a necessidade de se modernizar as forças policiais dos diferentes estados como forma de se diminuir essa constância.

Conforme matéria publicada em jornal de grande circulação, a fim de evitar que a exceção se transforme em regra, ou mesmo que haja uma "utilização casuística, pontual, e até mesmo a politização do emprego das Forças Armadas" (GOIS, 2018), em matéria de GLO, é preciso, urgentemente, aprimorar os órgãos de segurança pública, provendo-lhes as condições necessárias para o efetivo cumprimento das atribuições constitucionais que lhes foram conferidas pela Lei Maior da República.

Em suma, é necessário revigorar, em todos os aspectos possíveis, as forças policiais do país, resgatando-lhes o imprescindível prestígio institucional, o que demanda a adoção de uma série de medidas, tais como: investimentos em formação e treinamento policial, inteligência, tecnologia e equipamentos (armamentos, viaturas, coletes balísticos etc.), estabelecimento de consistentes protocolos de atuação operacional, criação de condições dignas de trabalho, acompanhamento da saúde física e mental do profissional, dentre outros aspectos fundamentais para que a autoestima dos integrantes dos órgãos policiais seja elevada.

$\mathrm{O}$ art. $5^{\circ}$, caput, da Constituição Federal de 1988, confere à segurança o status de direito individual fundamental. Por sua vez, o art. 6o, caput, trata-a como um direito social. Retomando o art. 144, caput, da Constituição Federal, anteriormente citado, pelos aspectos finalístico e classificatório, este assevera que "a segurança pública, dever do Estado, direito e responsabilidade de todos, é exercida para a preservação da ordem pública e da incolumidade das pessoas e do patrimônio" (BRASIL, 1988).

Em seguida, esta última norma jurídica elenca, taxativamente, diversos órgãos que integram o sistema constitucional da segurança pública: Polícia Federal, Polícia Rodoviária Federal, Polícia Ferroviária Federal (inexistente na atualidade), Polícias Civis, Polícias Militares e Corpos de Bombeiros Militares. O art. 144, § 8o, da CF/1988, por sua vez, estabelece que "os Municípios poderão constituir guardas municipais destinadas à proteção de seus bens, serviços e instalações, conforme dispuser a lei”.

Uma interpretação conjugada dos referidos dispositivos permite inferir que a Constituição, "Ao atribuir ao Estado o dever pela segurança pública, reconhece-a como serviço público a ser garantido pela máquina estatal", figurando, pois, como um "direito inalienável de todos os cidadãos" (FONTOURA; RIVERO; RODRIGUES, 2009). Nesse sentido, Jorge da Silva (2008) explica que, "em se tratando de segurança pública, não se pode tomar a palavra 'pública' no sentido usual, sendo mais acertado tomá-la como se referindo ao direito de todos os cidadãos de serem protegidos contra riscos a que possam estar expostos no espaço público e em casa" (SILVA, 2008).

Do mesmo modo, ao tratá-la como "responsabilidade de todos", a Lei Maior evidencia a importância da participação social na matéria em questão. 
[...] a definição da segurança também como responsabilidade de todos pode ser interpretada à luz da necessidade de que haja participação social nas políticas públicas relacionadas a esse campo. Adicionalmente, é possível compreender que a segurança pública não pode ser vista apenas como atribuição do Estado, uma vez que a sociedade tem um papel importante não somente na participação e controle das políticas, como também na socialização dos indivíduos, na perpetuação dos mecanismos informais de controle social e de autocontrole, a partir da perspectiva de que não é somente o controle pelo Estado que garante a segurança de todos. (FONTOURA; RIVERO; RODRIGUES, 2009)

Malgrado a cristalina redação do art. 144, caput, da Constituição Federal de 1988, segundo o qual a segurança pública constitui dever do Estado, direito e responsabilidade de todos, o Estado brasileiro, notadamente sua vertente legislativa, trata a

[...] segurança pública eminentemente sob o prisma penal, em detrimento de uma abordagem com foco na prevenção à violência, na melhor integração das forças de segurança ou, menos ainda, na coordenação de políticas públicas multissetoriais distintas da justiça criminal. (HOMERIN, 2017)

Assim, conforme reconhecem Fontoura et al (2009), "para enfrentar os problemas de criminalidade e violência atualmente existentes no Brasil o papel das polícias e a atuação destas tem se tornado essencial, o que não significa desconhecer a existência de outros fatores determinantes" (FONTOURA; RIVERO; RODRIGUES, 2009).

Apesar de a expressão ordem pública ter sido mencionada no caput do art. 144 da Constituição, esta, de maneira correta, não esboçou qualquer tentativa de conceituá-la, preferindo deixar essa tarefa para a doutrina especializada. Trata-se, portanto, daquilo que se convencionou chamar de conceito jurídico indeterminado, cuja exata dicção demanda uma análise de um contexto normativo mais amplo (isto é, sob o prisma sistemático) do Texto Magno. Nesse sentido, cumpre consignar que a Carta vigente, de modo constitucionalmente inédito, consagrou um capítulo próprio para o tratamento do tema segurança pública: Capítulo III do Título V - Da Defesa do Estado e das Instituições Democráticas (BRASIL, 1988). Conforme explica Ricardo Fiúza (1987-1988), "atendendo aos apelos comunitários e de nossa sociedade como um todo, surge a necessidade de se dotar a Constituição Federal de um título denominado Da Segurança Pública" (ASSEMBLEIA..., 1987-1988). A nosso ver, a Assembleia Nacional Constituinte (1987-1988) acertou ao conferir assento constitucional à matéria, mormente por inseri-la no âmbito das instituições democráticas, o que implica em compreender as instituições policiais como organismos voltados para a defesa do Estado $e$ da democracia. Afinal, como se vê, a expressão Da Defesa do Estado e das Instituições Democráticas (Título V da CF/1988) possui, em sua redação, a conjugação aditiva "e".

Portanto, uma interpretação sistemática permite afirmar que a expressão ordem pública (mencionada no caput do art. 144 da CF/88) guarda estreita relação com a ordem do Estado Democrático. Assim, não se admite, por parte dos organismos policiais, a prática de ações que possam ser rotuladas como antidemocráticas, tais como a tortura, o abuso de autoridade, a discriminação, a intolerância e a perseguição a grupos minoritários. Do mesmo modo, é inconcebível que o ente estatal quede inerte quanto ao seu dever de inovar em termos de segurança pública a fim de prover à população a tão necessária sensação de segurança. Afinal, consoante adverte Weichert:

A limitação da liberdade civil por decorrência da insegurança é visível no cotidiano. Em toda a população se tomam decisões sobre mobilidade considerando-se prioritariamente o fator "lugar menos perigoso." (WEICHERT, 2017) 
Fontoura et al (2009) apontam uma das possíveis causas para inércia:

\begin{abstract}
No caso das políticas de segurança, pode-se afirmar que os riscos de qualquer ação são altos, já que, se por um lado qualquer melhora indicada pela diminuição da criminalidade pode acarretar grandes benefícios políticos, por outro lado, um equívoco nesta área altamente visível, que permanece na mira constante da opinião pública, pode trazer perdas enormes aos seus responsáveis. Portanto, sendo área altamente sensível, poucos são os políticos que costumam arriscar grandes mudanças. (FONTOURA; RIVERO; RODRIGUES, 2009)
\end{abstract}

Weichert também aduz que a "falta de promoção e garantia de direitos civis, por decorrência da insegurança pública, qualifica a nossa democracia como 'disjuntiva' e 'incivil', ou uma 'democracia sem cidadania'” (WEICHERT, 2017).

Em um contexto democrático, a atuação policial deve estar fundamentada "na proteção aos cidadãos de maneira democrática e equitativa” (FONTOURA; RIVERO; RODRIGUES, 2009), cabendo às instituições policiais funcionar como um verdadeiro instrumento de promoção de direitos civis, políticos, econômicos, sociais, culturais etc.

\footnotetext{
Assim, entre os requisitos para a consolidação do Estado Democrático de Direito encontra-se o exercício e a garantia de direitos civis, o que pressupõe níveis razoáveis de segurança pública. Afinal, a carência de segurança pública é inibidora direta do gozo das liberdades individuais e coletivas, a começar pela autonomia de ir e vir. A presença de elevadíssimos índices de criminalidade é, destarte, um dos fatores que impede a consolidação de uma democracia plena, na medida em que obstrui de modo significativo o gozo de direitos civis. Esse déficit democrático mostra-se ainda mais grave em sociedades cujos órgãos do sistema de segurança pública e de justiça são responsáveis pela prática rotineira de violações aos direitos humanos. (WEICHERT, 2017)
}

A breve digressão acima a respeito do desenho institucional do sistema constitucional da segurança pública do Brasil objetiva demonstrar que, não obstante terem sido idealizados para a importante missão de preservar a ordem do Estado Democrático, os organismos policiais, paradoxalmente, não estão sendo contemplados com os meios necessários para o fiel cumprimento da nobre atribuição que lhes foi conferida pela Lei Magna do País, o que limita sobremaneira a concretização do direito insculpido nos mencionados arts. $5^{\circ}$ caput, $6^{\circ}$, caput, e 144, caput, da CF/1988.

\title{
O SUCATEAMENTO DAS FORÇAS POLICIAIS PELOS OLHOS DA IMPRENSA
}

Conforme Barroso (2017), "Falta de investimento financeiro nas instituições de segurança pública, tanto em relação ao pessoal quanto aos meios para cumprir seu trabalho", bem como "baixos salários, condições precárias, falta de recursos materiais e armamento defasado" (BARROSO, 2017) são pautas presentes entre os profissionais do segmento da segurança pública.

Como rotineiramente vem sendo noticiado, o sistema de segurança pública do País beira ao colapso, seja pela frequente falta de integração entre as aludidas instituições elencadas no art. 144 da Constituição, seja em decorrência dos problemas relacionados aos insuficientes recursos financeiros da Pasta. Apenas para exemplificar uma das imperfeições do sistema, sabe-se que as Polícias Militares do Brasil, por diversas razões, inclusive de ordens cultural e financeira, não preservam satisfatoriamente o local de infração penal, ao passo que as Polícias Civis, também por vários motivos, não conseguem investir em rotinas e protocolos 
investigativos, o que faz com que o seu produto institucional (notadamente o inquérito policial) seja, de modo geral, pouco consistente, contribuindo, assim, para os baixos índices de elucidação delitiva com os quais convivemos no País.

[...] em se tratando da apuração de crimes [...] a polícia brasileira vem funcionando como se fosse uma grande firma de detetives privados, e os governantes e autoridades, como seus proprietários. Este talvez seja o principal fator de impunidade no Brasil, pois o criminoso sabe que a possibilidade de ser descoberto, incriminado com provas cabais e preso é remotíssima. (SILVA, 2008, p. 329-330)

Aliás, sob o aspecto financeiro, a carência abrange desde os equipamentos mais básicos - armas de fogo, munições, coletes balísticos, fardamentos, viaturas, materiais periciais etc. - ao efetivo existente nas instituições policiais. A título de ilustração, e de acordo com o levantamento realizado por veículo da grande imprensa junto às entidades de classe de 11 estados da Federação - os quais concentram 3.171 municípios -, no ano de 2017, 1.684 entes municipais estavam sem delegados de polícia, o que, em última análise, compromete a essência do trabalho das Polícias Judiciárias, notadamente o registro e a investigação das infrações penais, explicando, de certa maneira, o baixo índice de elucidação delitiva existentes no Brasil.

Em alguns casos, especialmente nas áreas rurais, moradores chegam a andar mais de 100 quilômetros para conseguir registrar um boletim de ocorrência, tirar o RG ou mudar a documentação do carro. Sem pessoal suficiente para investigar, crimes ficam sem solução e inquéritos se acumulam. A falta de policiais também traz uma série de problemas para os próprios delegados, que são obrigados a acumular mais de um posto, sem receber mais para isso, e a percorrer centenas de quilômetros para acompanhar ocorrências.

Os governos estaduais argumentam que algumas dessas cidades estão sem responsável pela Polícia Civil porque são muito pequenas. Afirmam que tentam organizar a distribuição dos profissionais de acordo com as regiões. Em pelo menos dois estados, Pernambuco e São Paulo, delegados relataram que a falta de investigação nas cidades pequenas levou grupos criminosos a apostarem em roubos a caixas eletrônicos.

Minas Gerais é o estado com mais cidades sem delegado, entre as que responderam. Dos 853 municípios mineiros, 607 não têm delegado, de acordo com o sindicato da categoria. Ao contrário de outros estados, que possuem institutos responsáveis pela emissão do RG e de documentos de veículos, em Minas o documento é impresso na delegacia. Quando não encontra um delegado, o morador precisa ir a outra cidade. (PRADO; DANTAS, 2017, p. 3)

Ainda de acordo com a mesma matéria, "dos 246 municípios de Goiás, 162 não têm delegados e o déficit atual, segundo a assessoria da Polícia Civil [de Goiás], é de 193 profissionais". Da mesma forma, consoante os "dados fornecidos pelo diretor da Associação dos Delegados de Polícia do Ceará, não há delegados em 86 municípios dos 184 do estado”, o que, segundo a referida representação de classe, "prejudica o atendimento porque a população deixa de registrar ocorrência"; ademais, "quando o crime acontece, o delegado chega bem depois ao local e tem dificuldade até para encontrar testemunhas para ouvir depoimento", fatores que, sem sombra de dúvida, comprometem fortemente aquilo que se denomina de investigação imediata, fundamental para o sucesso da apuração da autoria e materialidade delitiva (PRADO; DANTAS, 2017, p. 3).

O problema (carência de efetivo) repete-se no Piauí e no restante do País: "o presidente da Federação Nacional dos Delegados de Polícia Civil, Rodolfo Laterza, projeta um déficit de 
delegados de aproximadamente 6 mil profissionais em todo o país. Ele cita o Piauí, onde 16o delegados precisam dar conta do trabalho de 224 cidades" (PRADO; DANTAS, 2017, p. 3).

Um quadro semelhante é encontrado quanto às instalações prediais, viaturas e equipamentos necessários para o bom desempenho dos trabalhos afetos à Polícia Civil do Estado do Rio de Janeiro. O cenário narrado na reportagem À Beira do Colapso (BOTTARI; TEIXEIRA; HERINGER, 2018, p. 8) é digno de registro, principalmente em se tratando do estado que tem como capital a internacionalmente conhecida Cidade Maravilhosa, a segunda mais importante do País, porta de entrada do turismo no Brasil. A reportagem descreve como, no início de 2018, pessoas que chegavam para fazer registro de ocorrência criminal encontravam a delegacia do Engenho Novo, responsável por investigações no bairro e em outros adjacentes.

\begin{abstract}
Dois cones foram colocados em frente a uma porta quebrada; cadeiras do saguão têm o forro rasgado. $\mathrm{O}$ banheiro masculino se encontra interditado, o feminino pode ser usado, desde que alguém segure uma maçaneta que não fecha. No mesmo horário, boletins de ocorrência são feitos na 22 $2^{\underline{a}}$ DP (Penha) graças ao comércio da área, que fez uma doação de papéis. Mas, do lado de fora, uma viatura chama a atenção: de tão carecas, os pneus mais parecem tiras de borracha lisa, e a lataria apresenta várias deformidades. (BOTTARI; TEIXEIRA; HERINGER, 2018, p. 8)
\end{abstract}

Além de descrever o estado em que se encontra a delegacia, a reportagem também apurou dados sobre a situação financeira da corporação de Policia Civil:

A penúria da Polícia Civil é enorme. De acordo com dados do Sistema Integrado de Gestão Orçamentária, Financeira e Contábil do Rio de Janeiro (Siafe-Rio), em 2017, a corporação recebeu autorização para gastar somente $\mathrm{R} \$ 12$ milhões com manutenção de atividades operacionais e administrativas, apesar de a Lei Orçamentária ter previsto uma verba de R\$23,3 milhões. Ainda assim, só conseguiu pagar metade dos serviços, e, por isso, começou este ano devendo R\$ 6,4 milhões. (BOTTARI; TEIXEIRA; HERINGER, 2018, p. 8)

Isso afeta não apenas o registro de ocorrências de crimes, mas também o trabalho da polícia técnico-científica:

[...] Entre as funções atribuídas à rubrica estava a elaboração de laudos de mortes violentas: foram no ano passado, registradas 6.731 no estado. Quem trabalha no setor se queixa da escassez de insumos fundamentais para as análises. Segundo um perito que pediu para não ser identificado, faltam luzes forenses e hastes plásticas capazes de indicar trajetos de projéteis (produtos bastante utilizados na investigação de casos de bala perdida), além de reagentes:

— O prédio do Instituto Médico-Legal está funcionando próximo ao colapso. A higiene é péssima, a recepção está com banheiros interditados. O setor de necropsia tem paredes, portas e pisos inadequados para a atividade fim. Há fissuras e placas descolando em várias salas, o que favorece a proliferação de bactérias. Portas feitas com compensado de madeira estão arrebentadas, mofadas e contaminadas por fluídos cadavéricos. Arcondicionado e exaustão deficientes causam constate mau cheiro. Estamos também enfrentando carência de reagentes químicos, luvas, aventais, mangotes e máscaras faciais. Necropsias vêm sendo realizadas com facões de açougue, serrotes de serralheiro, conchas e facas de cozinha. Exames de detecção de projétil deixam de ser realizados porque os aparelhos de raios X são ruins. (BOTTARI; TEIXEIRA; HERINGER, 2018, p. 8)

A situação financeira não é melhor na Polícia Militar do Estado do Rio de Janeiro. Conforme anota o Coronel PM Luis Cláudio Laviano, então Comandante Geral da PMERJ, "a falência do Estado se reflete na corporação" (ARAÚJO, 2018, p. 15). Segundo dados relativos 
ao mês de fevereiro de 2018, levantados por NUNES et al. (2018, p. 7), das 6.685 viaturas da Corporação, 1.838 estão fora das ruas aguardando manutenção. Invariavelmente, com menos viaturas nas ruas, o patrulhamento motorizado da Corporação fica comprometido, prejudicando, por conseguinte, o emprego dinâmico do policiamento ordinário.

Aliás, tal quadro financeiro no qual se encontram ambas as Polícias já foi, inclusive, diagnosticado pela equipe do General Braga Netto, Interventor Federal na área de segurança pública, conforme registra a reportagem abaixo:

As secretarias de Segurança (PM e Polícia Civil) e de Administração Penitenciária não têm recursos para novos investimentos. O dinheiro que o governo federal deve destinar para a intervenção no Rio não cobre nem mesmo as dívidas do ano passado (restos a pagar) da área de segurança. [...].

Um levantamento feito em fevereiro por assessores do General mostrou que as secretarias de Segurança (PM e Polícia Civil) e de Administração Penitenciária (Seap) não têm recursos para novos investimentos. As duas pastas estão sob o controle do interventor. Na ponta do lápis, as dívidas incluem R \$ 1,6 bilhão em restos a pagar (dívidas) de $2016 \mathrm{e}$ 2017 e cerca de R\$ 1,5 bilhão de gastos previstos para este ano. [...].

- A falta de recursos é o grande gargalo enfrentado pela segurança pública no estado e um problemão para a intervenção federal. Temos, por exemplo, quatro mil policiais concursados que não podem ser chamados por falta de dinheiro - disse uma fonte ouvida pelo GLOBO. (WERNECK; TEIXEIRA; PEREIRA, 2018, p. 9)

Apesar de ser evidente que o enfrentamento do problema da criminalidade e da violência no Brasil requer muito mais do que uma simples dotação orçamentária capaz de financiar a segurança pública, é preciso que o Estado brasileiro compreenda a importância de se dotar as forças de segurança pública dos recursos necessários para o adequado cumprimento de suas atribuições constitucionais e legais, sem os quais os problemas detectados pelo Gabinete de Intervenção Federal no Rio de Janeiro - muitos dos quais também ocorrem em outros estados da Federação - não serão solucionados, retroalimentando o emprego casuístico das Forças Armadas em matéria de garantia da lei e da ordem (GLO).

Com efeito, um orçamento condizente com a relevância da área é fundamental para melhorar o serviço público prestado pelas Polícias do Brasil, capacitando-as efetivamente para a preservação da ordem do Estado Democrático. Precisamos evoluir quanto a tal quesito, inclusive refletir sobre a possibilidade de conferir autonomia financeira às Polícias (Federal, Civil, Militar etc.), exatamente como acontece com outras instituições que compõem o Sistema de Justiça Criminal, tais como o Ministério Público e o Poder Judiciário, ambos igualmente comprometidos com a ordem do Estado Democrático.

\section{CONSIDERAÇÕES FINAIS}

Quando se fala em segurança pública o primeiro pensamento que se tem está relacionado à questão da violência, uma das principais causadoras da sensação de insegurança nos grandes centros urbanos. A violência urbana é um dos problemas críticos com os quais diferentes países precisam lidar em suas políticas públicas. Ela atinge, nos dias de hoje, a maioria das cidades brasileiras e se reflete em diferentes áreas da vida dos cidadãos, como trabalho, lazer, locomoção etc.

O trabalho discutiu os conceitos de segurança pública e de ordem pública, apresentou o conceito de segurança pública pela perspectiva da Carta Magna, que a entende como um direito social e um dever do Estado, e que como direito e responsabilidade de todos cabe a ela 
preservar a ordem pública e a integridade das pessoas e do patrimônio. Logo, estes conceitos não se explicam de forma isolada, visto que se qualificam por uma relação de causalidade.

A Constituição Federal elenca quais são os órgãos que integram o sistema constitucional da segurança pública: Polícia Federal, Polícia Rodoviária Federal, Polícia Ferroviária Federal (inexistente na atualidade), Polícias Civis, Polícias Militares e Corpos de Bombeiros Militares, e atribui aos municípios autonomia para criarem Guarda Municipal de acordo com suas necessidades. Para formar um sistema de segurança pública é preciso que estes órgãos interajam em torno de um objetivo comum.

Em seu art. 142, a Constituição esclarece que as Forças Armadas se destinam à defesa da pátria e garantia dos poderes constitucionais e, diante da necessidade, a garantia do cumprimento das leis e a preservação da ordem pública. Mas foi mostrado que, mesmo diante da possibilidade de uso das instituições militares em missões de segurança pública, o uso constante das Forças Armadas em GLO, como vem acontecendo no país há algum tempo, expõe a emergência de se debater sobre a necessidade de modernização das forças policiais como forma de se diminuir essa constância.

Por fim, diversas matérias publicadas em veículos de comunicação de grande circulação no país mostram como os órgãos que integram a segurança pública no Brasil vêm passando por um longo processo de sucateamento e se tornando incapazes de cumprir de forma efetiva as atribuições que lhes foram atribuídas pela Constituição Federal. Como consequência o que temos é um sistema de segurança pública frágil e que não consegue apresentar resultados satisfatórios para a população.

\section{REFERÊNCIAS}

ASSEMBLÉIA Nacional Constituinte. (1987-1988), Comissão da Organização Eleitoral, Partidárias e Garantias das Instituições. Subcomissão de Defesa do Estado, da Sociedade e de sua Segurança. “Anteprojeto". Relatório. Relator: Deputado Constituinte Ricardo Fiuza - PFL/PE. Volume 132. Brasília: Centro Gráfico do Senado Federal. Disponível em: <https:// www.camara.leg.br/internet/constituicao2oanos/DocumentosAvulsos/vol-132.pdf>. Acesso: O2 fev. 2019.

BARROSO, Priscila Farfan. O Sentimento de Insegurança e a Armadilha da Segurança Privada: Reflexões Antropológicas a Partir de um Caso no Rio Grande do Sul. Revista Brasileira de Segurança Pública, São Paulo, v. 11, no 2, ago./set., p. 148-163, 2017.

BRASIL. Constituição da República Federativa do Brasil. 1988. Disponível em: <http://www. planalto.gov.br/ccivil_03/Constituicao/Constituicao.htm>. Acesso: 02 fev. 2019.

CANO, Ignacio. Políticas de segurança pública no Brasil: tentativas de modernização e democratização versus a guerra contra o crime. Sur Revista Internacional de Direitos Humanos. Número 5, Ano 3. (2006),

FONTOURA, Natália de Oliveira; RIVERO, Patricia Silveira; RODRIGUES, Rute Imanishi. (2009), Segurança Pública na Constituição Federal de 1988: Continuidades e Perspectivas. Políticas Sociais: Acompanhamento e Análise, Vinte Anos da Constituição Federal, no 17, v. 3, p. 136-198, Ipea, Diretoria de Estudos e Políticas Sociais, Brasília. 
HOMERIN, Janaína Camelo. (2017), O Papel de uma Legislação Penal mais Responsável naRedução do Fluxo de Entrada no Sistema Prisional. Revista Brasileira de Segurança Pública, São Paulo, v. 11, no 2, ago./set., p. 30-46.

INSTITUTO de Segurança Pública/ISP. (2019), Séries históricas anuais de taxa de letalidade violenta no estado do Rio de Janeiro e grandes regiões. Disponível em: http://www.ispdados. rj.gov.br/Arquivos/SeriesHistoricasLetalidadeViolenta.pdf. Acesso: 02 fev. 2019.

MONTESQUIEU, C. de S. (20oo), O Espírito das Leis. Introdução, trad. e notas de Pedro Vieira Mota. $7^{\text {a }}$ ed. São Paulo. Saraiva.

ONU. Declaração Universal dos Direitos Humanos. (1948), Assembleia Geral das Nações Unidas em Paris. $10 \mathrm{dez}$ 1948. Disponível em: <http://www.dudh.org.br/wpcontent/uploads/2014/12/ dudh.pdf>. Acesso: 02 fev. 2019.

ORGANIZAÇÃO DOS ESTADOS AMERICANOS. Conceito de segurança pública. Disponível em: < http://www.oas.org/pt/topicos/seguranca_publica.asp>. Acesso: 02 fev. 2019.

PNUD Programa das Nações Unidas para o Desenvolvimento. (2013), Relatório Regional de Desenvolvimento Humano 2013-2014. SEGURANÇA CIDADÃ COM ROSTO HUMANO: DIAGNÓSTICO E PROPOSTAS PARA A AMÉRICA LATINA. Disponível em: < http://www. latinamerica.undp.org/content/dam/rblac/docs/Research\%2oand\%2oPublications/IDH/ Resumen\%2oIDH\%2oportugues_completo_.pdf>. Acesso: 02 fev. 2019.

ROCHA, Claudionor. BOAS PRÁTICAS EM SEGURANÇA PÚBLICA. (2016), Consultor Legislativo da Área XVII. Segurança Pública e Defesa Nacional. Disponível em: <https://www2. camara.leg.br/atividade-legislativa/estudos-e-notas-tecnicas/publicacoes-da-consultorialegislativa/areas-da-conle/tema21/boas-praticas-em-seguranca-publica>. Acesso: 02 fev. 2019.

ROLIM, Marcos. (2007), Caminhos para a inovação em segurança pública no Brasil. Revista Brasileira de Segurança Pública, São Paulo, v. 1, no 1.

SILVA Jorge da. (2008), Criminologia Crítica: Segurança e Polícia. Rio de Janeiro: Forense Jurídica.

WEICHERT, Marlon Alberto. (2017), Violência Sistemática e Perseguição Social no Brasil. Revista Brasileira de Segurança Pública, São Paulo, v. 11, no 2, ago./set., p. 106-128.

\section{Fontes da imprensa}

ARAÚJO, Vera. (15/04/2018), "Convênios para Cessão de Policiais deram Fôlego à PM". O Globo, p. 15.

BOTTARI, Elenilce; TEIXEIRA, Fábio; HERINGER, Carolina. (o9/o2/2018), "À Beira do Colapso". O Globo, p. 8.

CARIELLO, Gabriel. (16/o3/2018), "Especialistas: Crime Ultrapassa Limite”. O Globo, p. 13. 
GOIS, Ancelmo. (23/03/2018), O Globo, Ponto Final, p. 23.

NUNES, Marcos; SOARES, Rafael; ARAÚJO, Vera. (23/o2/2018), “Tropa Será Convocada”. O Globo, p. 7 .

PRADO, Chico; DANTAS, Tiago. (26/12/2017), "Investigação Comprometida". O Globo, País, p. 3. 2013.

SENADO Notícias. (19/o9/2017), "Segurança Pública: Protagonismo da União e Integração entre Estados pode Diminuir Violência”. Disponível em: https://www12.senado.leg.br/noticias/ materias/2017/o9/19/seguranca-publica-maior-protagonismo-da-uniao-e-integracao-entreestados-pode-diminuir-violencia. Acesso: 02 fev. 2019.

WERNECK, Antônio; TEIXEIRA, Fábio; PEREIRA, Paulo Celso. (20/o3/2018), "General quer 3,1 bi, mas Temer promete liberar apenas um terço". O Globo, p. 9. 